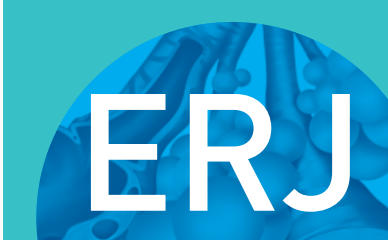

open research
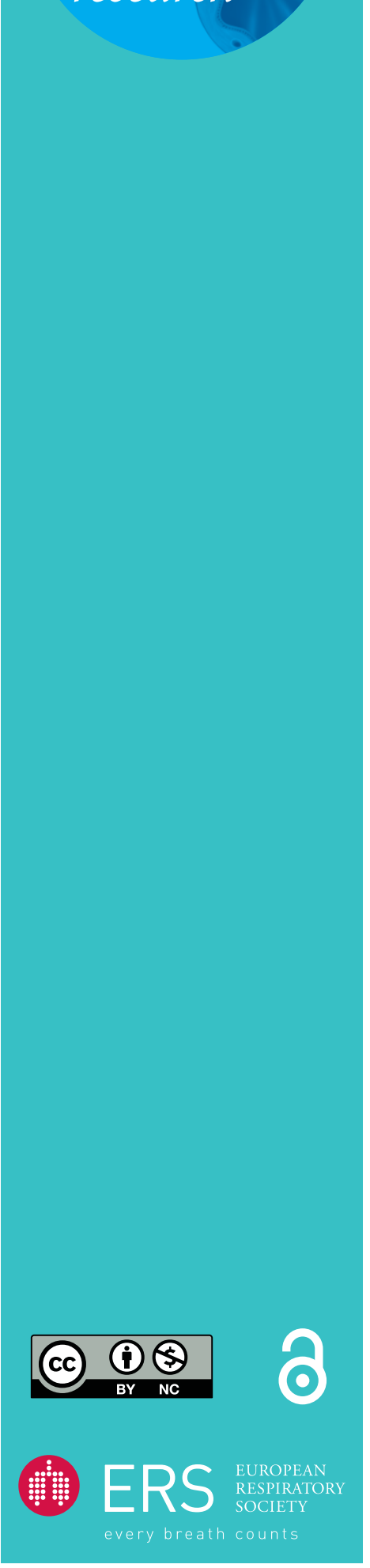

\section{Biomarker-based corticosteroid adjustment in severe asthma: a modified Delphi consensus}

\section{To the Editor:}

Asthma is managed using "step-wise" adjustment of corticosteroid therapy to achieve asthma control. When corticosteroid treatment is adjusted using sputum eosinophil count or exhaled nitric oxide fraction, exacerbations are reduced [1, 2]; however, implementation in clinical care has been slow. In parallel, airway transcriptomic analysis has demonstrated that type 2 eosinophilic inflammation is absent in many patients with minimal response to corticosteroid treatment [3-5]. The UK Refractory Asthma Stratification Programme (RASP-UK) (http://rasp.org.uk/) is exploring non-sputum biomarker-based strategies to target corticosteroid treatment in severe asthma [6,7], and sought to determine clinician and patient views on clinically relevant reductions in corticosteroid treatment.

Three expert physician groups in severe asthma management participated in an online anonymous modified Delphi process [8] (three rounds): 1) RASP-UK Investigators ( $\mathrm{n}=21), 2$ ) UK severe asthma physicians not in RASP-UK $(\mathrm{n}=16)$ and 3) the European Respiratory Society Severe Asthma Clinical Research Collaboration [9] $(\mathrm{n}=22) .41$ out of 59 physicians completed the process to achieve final statement consensus ( $>75 \%$ agreement) (figure 1). An identical process using a patient-focused questionnaire was sent to severe asthma patients from Asthma UK's Expert Patient Group (two rounds achieved consensus; 16 out of 23 completed the first round and 12 completed the second round). A RASP-UK investigator and statistician composed the questions. After the first round, the questions of subsequent rounds were adapted based on the responses from the previous round.

The final consensus statements and levels of agreement were as follows.

\section{Statement 1}

Do you believe that biomarker-based adjustment of corticosteroid dose is currently the optimal way to adjust corticosteroid treatment in patients with severe asthma compared to symptoms, lung function and exacerbation history?

Consensus not achieved

\section{Physician view}

Only $39 \%$ of the European group (group 3) agreed, compared to $68 \%$ of the RASP-UK (group 1) and $67 \%$ of the UK non-RASP (group 2) physicians. Currently, $44 \%$ of European physicians use biomarker-based corticosteroid adjustment routinely compared with 95\% (group 1) and 100\% (group 2).

\section{Patient view}

No consensus was reached on patient preference on corticosteroid adjustment using symptoms or biomarkers (50\% each). The majority (75\%) believed their corticosteroid was currently adjusted using symptoms/lung function.

@ERSpublications

UK asthma physicians are supportive of biomarker-based steroid adjustment, but European physicians need more evidence http://ow.ly/sTrf30my3jw

Cite this article as: Gallagher NE, Hanratty CE, Humbert M, et al. Biomarker-based corticosteroid adjustment in severe asthma: a modified Delphi consensus. ERJ Open Res 2018; 4: 00081-2018 [https://doi.org/10.1183/23120541.00081-2018].

Copyright (CERS 2018. This article is open access and distributed under the terms of the Creative Commons Attribution Non-Commercial Licence 4.0. 
Definition of problem

Selection of expert panel

First round of Delphi

Second round of Delphi

Third round of Delphi
Uncertainty as to clinicians' opinions of using a biomarker-based management approach to corticosteroid adjustment versus symptoms, lung function and exacerbation history

What level of steroid reduction is required to define using a biomarker-based algorithm as clinically worthwhile?

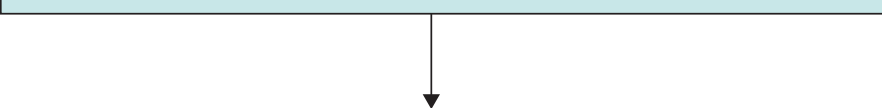

Respiratory physicians specialising in the management of patients with difficult asthma:

59 specialist physicians selected with experience in treating severe asthma

Group 1: RASP-UK PIs

Group 2: UK severe asthma physicians not involved in RASP-UK

Group 3: Members and collaborators with the European Severe Asthma Clinical Research Collaboration SHARP

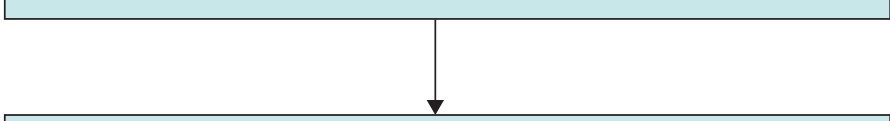

Questionnaire posted online with 10 questions

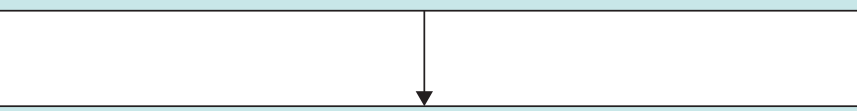

Results from first round summarised and participants agree or disagree with majority result

Participants could comment if necessary

Responses analysed for level of consensus
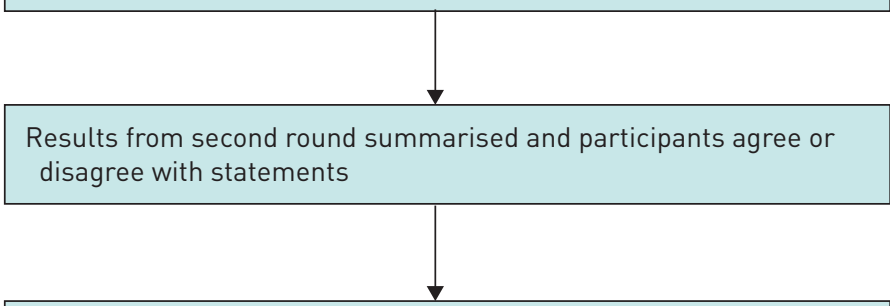

Results analysed for degree of consensus

FIGURE 1 Modified Delphi process used to reach a consensus among experts in severe asthma regarding the degree of benefit of biomarker-based adjustment of corticosteroid treatment required to make the conversion to a biomarker algorithm from current standard care worthwhile. RASP-UK: UK Refractory Asthma Stratification Programme; PI: principal investigator; SHARP: Severe Heterogeneous Asthma Research collaboration, Patient-centred.

\section{Statement 2}

Accepting that nonadherence may be both intentional and unintentional, do you agree that between $30 \%$ and $50 \%$ of severe asthma patients in the most severe and difficult asthma clinics are poorly adherent with inhaled corticosteroid treatment as the primary clinical problem?

Consensus achieved

\section{Physician view}

Group 1 felt this proportion was $30-50 \%$, group 2 thought $25-50 \%$ and group 3 thought $20-50 \%$.

\section{Patient view}

$94 \%$ of patients reported they would never miss taking their inhalers.

\section{Statement 3a}

Do you agree that at least $5 \mathrm{mg}$ (or $2.5 \mathrm{mg}$ if on $\leqslant 10 \mathrm{mg} \cdot \mathrm{day}^{-1}$ ) reduction in daily oral prednisolone would be regarded as a clinically meaningful reduction? 


\section{Statement 3b}

If you treat patients with asthma on maintenance oral steroids, do you agree that at least $25 \%$ of patients would be required to be on this optimised "lower" dose of daily oral prednisolone treatment to justify routine use of biomarker-based corticosteroid treatment adjustment in routine clinical care?

Consensus achieved

\section{Physician view}

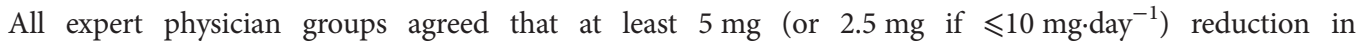
prednisolone was clinically meaningful. Group 1 thought that at least $25 \%$ of patients would need to make this reduction to justify a biomarker-based strategy, whilst groups 2 and 3 thought at least $20 \%$.

\section{Patient view}

$91 \%$ of patients felt any reduction in oral corticosteroids would make blood/breath tests worthwhile.

\section{Statement $4 a$}

Do you agree that in a severe asthma population on high-dose inhaled steroids $(2000 \mu \mathrm{g}$ beclomethasone dipropionate equivalent dose) that at least a $500 \mu \mathrm{g}$ reduction in daily inhaled corticosteroid treatment would be regarded as a clinically meaningful dose reduction?

Consensus not achieved

\section{Statement $4 \mathrm{~b}$}

Do you agree that at least $30 \%$ of patients would be required to be on this optimised "lower" dose of daily inhaled corticosteroid treatment to justify routine use of biomarker-based corticosteroid treatment adjustment in routine clinical care?

Consensus not achieved

\section{Physician view}

Group 1 agreed that at least $500 \mu \mathrm{g}$ reduction was clinically meaningful and group 2 thought this was at least $250 \mu \mathrm{g}$ reduction. For group 3,62\% felt that at least $250 \mu \mathrm{g}$ reduction was clinically meaningful (no consensus). Groups 1 and 2 agreed that at least 30\% of patients would need to be on this optimised lower dose to justify using a biomarker-based adjustment strategy; for group 3, 54\% felt that at least $40 \%$ of patients would need to achieve this (no consensus).

\section{Patient view}

$73 \%$ of patients felt that additional blood/breath tests would be worthwhile if they led to any reduction in inhaled corticosteroid treatment.

\section{Statement 5}

Accepting at least three exacerbations per year (requiring oral corticosteroid rescue therapy), do you agree that at least a $30 \%$ reduction per year would be an acceptable reduction to justify routine use of biomarker-based corticosteroid treatment adjustment?

Consensus achieved

\section{Physician view}

Group 1 agreed that at least a 30\% reduction in asthma exacerbations per year would justify routine use of biomarker-based corticosteroid treatment adjustment whereas groups 2 and 3 agreed that at least a 20\% reduction would justify routine use.

\section{Patient view}

$44 \%$ of patients had three or more asthma attacks in the previous year requiring oral corticosteroids. All patients thought that having regular blood and breath tests would be worthwhile if this prevented one attack. 


\section{Statement 6}

Excluding patients where persistent symptoms of cough, wheeze and breathlessness are due to comorbid conditions (e.g. obesity, vocal cord dysfunction, dysfunctional breathing, rhinosinusitis, etc.), do you agree that at least $25 \%$ of remaining severe asthma patients in your clinic have persistent symptoms due to asthma that are not corticosteroid responsive?

Consensus achieved

\section{Physician view}

Groups 1 and 2 agreed at least 25\% and group 3 agreed at least 20\% of severe asthma patients have persistent symptoms due to asthma that are not corticosteroid responsive.

\section{Patient view}

$91 \%$ of patients agreed that not all their symptoms responded to inhaled or oral steroids.

The RASP-UK programme is exploring if a non-sputum biomarker-based adjustment of corticosteroid treatment is clinically more beneficial than standard care [7]. In this modified Delphi exercise, consensus was reached on all issues for groups 1 and 2. However, for group 3, consensus was not reached on a number of issues, including clinically meaningful dose reduction in inhaled corticosteroid treatment and proportion of patients reducing inhaled corticosteroid treatment to justify routine use of biomarkers. Overall, European experts appeared less supportive of biomarker-based corticosteroid adjustment compared to UK physicians and correctly stated that although sputum eosinophil count was evidence based, delivery was difficult in routine care and the optimal combination of non-sputum-based biomarkers was unknown $[10,11]$.

Patient views are critical in understanding acceptance of treatment strategies and there was no consensus on corticosteroid treatment adjustment using symptoms versus biomarkers, suggesting education may be required on the utility of biomarkers in targeting treatment. The majority felt any reduction in inhaled/ oral corticosteroid dose or eradicating one severe exacerbation would make biomarker tests worthwhile. Patients felt regular blood and breath tests were unlikely to improve adherence; however, this small motivated group reported never missing medication. The group of patients who took part in this survey volunteered for Asthma UK and some were also involved in the Patient Input Platform for the RASP-UK programme. These patients may, therefore, have had greater knowledge regarding severe asthma and biomarkers.

In conclusion, we present a consensus view of severe asthma expert physicians on non-sputum biomarker-based corticosteroid adjustment and the scale of benefit that would persuade them to use biomarkers in routine clinical care. A small number of nonconsensual issues were identified, where European group experts appeared to be less supportive of biomarker-based adjustment of asthma treatment compared to UK physicians.

Nicola E. Gallagher ${ }^{1}$, Catherine E. Hanratty ${ }^{1}$, Marc Humbert $\odot^{2,3}$, Elisabeth Bel ${ }^{4}$, Ratko Djukanovic ${ }^{5,6}$, Valerie Hudson ${ }^{7}$, Nile Amos ${ }^{7}$ and Liam G. Heaney ${ }^{1,6}$ on behalf of the RASP-UK Consortium

${ }^{1}$ Centre for Experimental Medicine, School of Medicine, Dentistry and Biomedical Sciences, Queen's University, Belfast, UK. ${ }^{2}$ Univ. Paris-Sud, Faculté de Médecine, Université Paris-Saclay, Le Kremlin-Bicêtre, France. ${ }^{3}$ Service de Pneumologie, Hôpital Bicêtre, Assistance Publique Hôpitaux de Paris, Le KremlinBicêtre, France. ${ }^{4}$ Academic Medical Centre of the University of Amsterdam, Amsterdam, The Netherlands. ${ }^{5}$ NIHR Southampton Biomedical Research Centre, Southampton, UK. ${ }^{6}$ RASP-UK, London, UK. ${ }^{7}$ Asthma UK RASP-UK Patient Input Platform, London, UK.

Correspondence: Nicola E. Gallagher, Centre for Experimental Medicine, School of Medicine, Dentistry and Biomedical Sciences, Queen's University, 97 Lisburn Road, Belfast BT9 7BL, UK.

E-mail: ngallagher17@qub.ac.uk

Received: June 042018 | Accepted after revision: Oct 222018

Acknowledgements: We would like to thank the physicians in both the UK and European Respiratory Society Severe Asthma Clinical Research Collaboration and the all the patients who took part in the modified Delphi process.

Conflict of interest: N.E. Gallagher has nothing to disclose. C.E. Hanratty has nothing to disclose. M. Humbert reports receiving grants, personal fees and nonfinancial support from GlaxoSmithKline, personal fees from AstraZeneca, Novartis and Roche, and grants and personal fees from Sanofi. E. Bel reports receiving research grants to her department and personal fees from AstraZeneca, Boehringer Ingelheim, GSK, Novartis and Roche. R Djukanovic reports 
receiving fees for lectures at symposia organised by Novartis and TEVA, consultation for these two companies as member of advisory boards, and participation in a scientific discussion about asthma organised by GlaxoSmithKline. He is a co-founder of, current consultant to and has shares in Synairgen, a University of Southampton spin out company. V. Hudson has nothing to disclose. N. Amos has nothing to disclose. L.G. Heaney reports having taken part in advisory boards and given lectures at meetings support by GlaxoSmithKline, Respivert, Merck Sharpe \& Dohme, Nycomed, Boehringer Ingelheim, Teva, Vectura, Novartis and AstraZeneca, and received sponsorship for attending international scientific meetings from AstraZeneca, Boehringer Ingelheim, Chiesi and Teva.

\section{References}

1 Petsky HL, Li A, Chang AB. Tailored interventions based on sputum eosinophils versus clinical symptoms for asthma in children and adults. Cochrane Database Syst Rev 2017; 8: CD005603.

2 Petsky HL, Kew KM, Turner C, et al. Exhaled nitric oxide levels to guide treatment for adults with asthma. Cochrane Database Syst Rev 2016; 9: CD011440.

3 Pavord ID, Brightling CE, Woltmann G, et al. Non-eosinophilic corticosteroid unresponsive asthma. Lancet 1999; 353: 2213-2214.

4 McGrath KW, Icitovic N, Boushey HA, et al. A large subgroup of mild-to-moderate asthma is persistently non-eosinophilic. Am J Respir Crit Care Med 2012; 185: 612-619.

5 Woodruff PG, Modrek B, Choy DF, et al. T-helper type 2-driven inflammation defines major sub-phenotypes of asthma. Am J Respir Crit Care Med 2009; 180: 388-395.

6 Heaney LG, Djukanovic R, Woodcock A, et al. Research in progress: Medical Research Council United Kingdom Refractory Asthma Stratification Programme (RASP-UK). Thorax 2015; 71: 187-189.

7 Hanratty CE, Matthews JG, Arron JR. A randomised pragmatic trial of corticosteroid optimization in severe asthma using a composite biomarker algorithm to adjust corticosteroid dose versus standard care: study protocol for a randomised trial. Trials 2018; 19: 5 .

8 Linstone H, Turoff M. The Delphi Method Techniques and Applications. Reading, Addison-Wesley, 1975.

9 European Respiratory Society. Clinical research collaborations. https://www.ersnet.org/research/clinical-researchcollaborations

10 Zervas E, Samitas K, Papaioannou AI, et al. An algorithmic approach for the treatment of severe uncontrolled asthma. ERJ Open Res 2018; 4: 00125-2017.

11 Schleich F, Sophie D, Renaud L. Biomarkers in the management of difficult asthma. Curr Top Med Chem 2016; 16: 1561-1573. 